Technical Note

\title{
Foraminoplastic Superior Vertebral Notch Approach with Reamers in Percutaneous Endoscopic Lumbar Discectomy : Technical Note and Clinical Outcome in Limited Indications of Percutaneous Endoscopic Lumbar Discectomy
}

\author{
Chul-Woo Lee, M.D., Ph.D., Kang-Jun Yoon, M.D., Ph.D., Sang-Soo Ha, M.D., Ph.D., Joon-Ki Kang, M.D., Ph.D. \\ Department of Neurosurgery, St. Peter's Hospital, Seoul, Korea
}

\begin{abstract}
To describe the details of the foraminoplastic superior vertebral notch approach (FSVNA) with reamers in percutaneous endoscopic lumbar discectomy (PELD) and to demonstrate the clinical outcomes in limited indications of PELD. Retrospective data were collected from 64 patients who underwent PELD with FSVNA from August 2012 to April 2014. Inclusion criteria were high grade migrated disc, high canal compromised disc, and disc protrusion combined with foraminal stenosis. The clinical outcomes were assessed using by the visual analogue scale (VAS), Oswestry Disability Index (ODI) and modified MacNab criteria. Complications related to the surgery were reviewed. The procedure used a unique approach, using the superior vertebral notch as the target and performing foraminoplasty with only reamers under C-arm control. The mean age of the 55 female and 32 male patients was 52.73 years. The mean F/U period was 12.2 \pm 4.2 months. Preoperative VAS (8.24 \pm 1.25$)$ and ODI (67.8 \pm 15.4$)$ score improved significantly at the last follow-up (VAS, 1.93 \pm 1.78 ; ODI, 17.14 \pm 15.7 ). Based on the modified MacNab criteria, excellent or good results were obtained in $95.3 \%$ of the patients. Postoperative transient dysthesia $(n=2)$ and reoperation $(n=1)$ due to recurred disc were reported. PELD with FSVNA could be a good method for treating lumbar disc herniation. This procedure may offer safe and efficacious results, especially in the relatively limited indications for PELD.
\end{abstract}

Key Words : Percutaneous endoscopic · Foraminoplasty $\cdot$ Superior vertebral notch.

\section{INTRODUCTION}

Percutaneous endoscopic lumbar discectomy (PELD) is one option to treat herniated lumbar disc disease. Regardless of many merits, such as less tissue trauma and shorter hospital stay, some cases like high migrated disc protrusion, high canal compromised disc, or foraminal stenosis have not been considered optimal indications for the endoscopic procedure ${ }^{16,18}$. Approach-related complications, like postoperative dysthesia and motor weakness due to upper root injury are of concern to performing PELD. To overcome these limitations and prevent unfavorable complications in PELD, various other approaches and techniques have been developed ${ }^{4,8,19,22)}$. Some authors have described the endoscopic foraminoplasty technique by using a drill, reamer, or laser in performing PELD ${ }^{2,5,7,11,12,19,24,29)}$. But, there are few reports ex- tensively detailing the method of foraminoplasty. We describe the details of a unique percutaneous endoscopic superior vertebral notch approach performed with the foraminoplastic technique using reamers under $\mathrm{C}$-arm control, and demonstrate the clinical results and efficacy in limited indications of PELD.

\section{MATERIALS AND METHODS}

\section{Patients population and outcome evaluation}

A retrospective review was performed on 589 patients who had undergone percutaneous endoscopic lumbar discectomy with foraminoplasty using the superior vertebral notch approach between August 2012 and April 2014 at single center. Among those patients, 64 patients were selected for this study. Inclusion criteria were patients who were preoperatively diagnosed with high

- Received : August 24, 2015 • Revised : January 13, 2016 • Accepted : January 16, 2016

- Address for reprints: Chul-Woo Lee, M.D., Ph.D.

Department of Neurosurgery, St. Peter's Hospital, 2633 Nambusunhwan-ro, Gangnam-gu, Seoul 06268, Korea

Tel : +82-2-1544-7522, Fax : +82-2-574-9414, E-mail : mannitol240@gmail.com

- This is an Open Access article distributed under the terms of the Creative Commons Attribution Non-Commercial License (http://creativecommons.org/licenses/by-nc/3.0) which permits unrestricted non-commercial use, distribution, and reproduction in any medium, provided the original work is properly cited. 
canal compromise disc (exceeding 50\% of the canal cross sectional area) (Fig. 1A), highly migrated disc (the extent of migration was larger than the measured height of the posterior marginal disc space) (Fig. 1B) and disc protrusion combined moderate to severe foraminal stenosis (based on the Wildermuth Grading System $^{26)}$ ) by lumbar MRI, and had radiculopathy that had not responded to more than 6 weeks of conservative treatment. Intracanalicular stenosis, pure foraminal stenosis, segmental instability, or coexisting pathologic conditions such as acute inflammation, infection, or tumor were excluded. Patient demographics and characteristics are summarized in Table 1. Patients were evaluated postoperatively with the Visual Analogue Scale (VAS) for leg pain, Oswestry Disability Index scores, and the modified
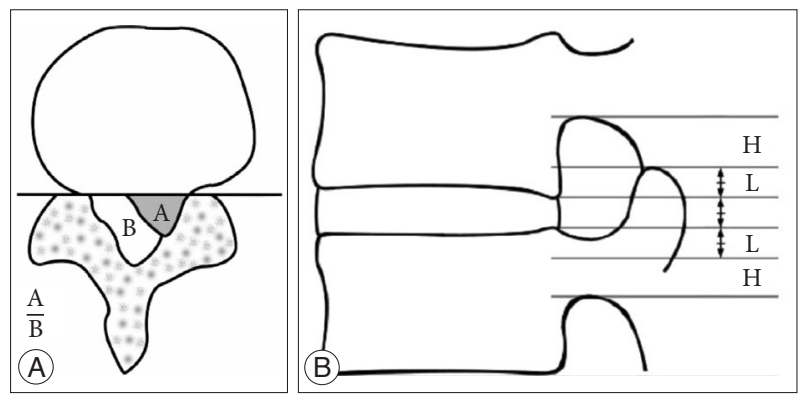

Fig. 1. A : Size of herniated disc. B : Size of the spinal canal.

Table 1. Patient demographics and characteristics

\begin{tabular}{lc}
\hline \multicolumn{1}{c}{ Data } & No. \\
\hline Sex & \\
Male & 39 \\
Female & 25 \\
Age & $52.73(22-69)$ \\
Follow up & $12.2 \pm 4.2$ months \\
Preoperative Diagnosis & \\
High grade migration & 38 \\
$\quad$ Superior & 18 \\
$\quad$ Inferor & 28 \\
High canal compromise & 8 \\
Combined foraminal stenosis & 10 \\
Spinal level involved & \\
L2-3 & 6 \\
L3-4 & 8 \\
L4-5 & 42 \\
L5-S1 & 8 \\
\hline
\end{tabular}

$\mathrm{MacNab}$ criteria. Complications related to the surgery and surgical outcome were reviewed. Statistical analysis for the comparison between pre- and post-operative clinical outcome was performed using a Student t-test, and $p$-values less than 0.05 were considered significant.

\section{Surgical methods}

The uniqueness of surgical technique in this study, which distinguishes it from previous standard PELD, is the use of the superior vertebral notch as the approach target to dock the guide rod. A comparison with standard PELD is summarized in Table 2, Fig. 2. PELD with FSVNA was performed with a complete endoscopic instrument system : THESSYS $^{\circledR}$ (joimax GmbH, Raumfabrik 33A, Amalienbadstraße, Karlsruhe, Germany) (Fig. 3).

\section{Anesthesia and operative position}

The procedure was performed under local anesthesia with the patient in the prone position on a C-arm fluoroscopic table. Conscious sedation with neuroleptic analgesia permitted continuous feedback from the patient during the entire procedure.

\section{Skin entry point}

The entry point was marked on the skin under fluoroscopic guidance. The entry point was determined by the point of intersection between the marked horizontal line and the oblique caudal directional line (Fig. 4). The entry point is usually 8-14 $\mathrm{cm}$ from the midline horizontally. The exact distance from the midline depends on the size of the foramen and the patient's

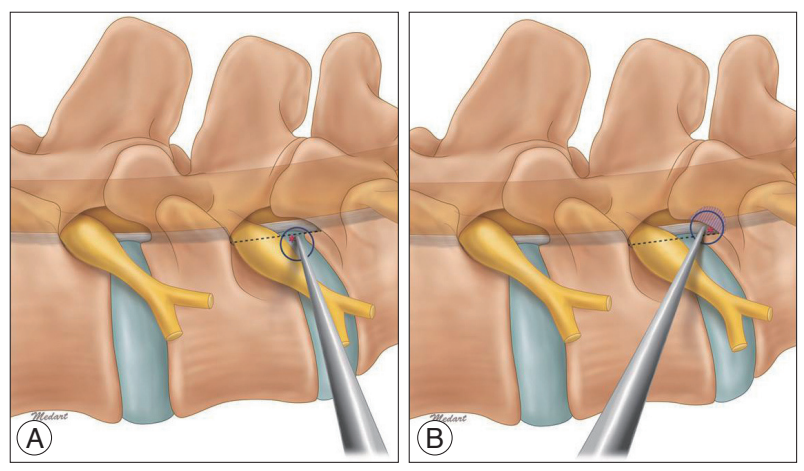

Fig. 2. Comparison between standard percutaneous endoscopic lumbar discectomy (PELD) and foraminoplastic superior vertebral approach (FSVNA) (A). Standard PELD (B). FSVNA Rod : approach trajectory, Asterisk: approach target, Blue circle : initial placement of working cannula, Dotted area : resected area by foraminoplasty.

Table 2. Comparison between standard PELD and FSVNA

\begin{tabular}{lll}
\hline & Standard PELD with/without foraminoplasty & FSVNA \\
\hline Approach target & Disc & Superior vertebral notch \\
Technique & Inside-outside & Outside-inside \\
Working area & Disc (sub-annular) & Spinal canal \\
Instruments during & Drill, laser, reamer & Reamer only \\
Monitoring during approach and foraminoplasty & Under endoscopic vision & Under C-arm view \\
\hline
\end{tabular}

PELD : percutaneous endoscopic lumbar discectomy, FSVNA : foraminoplastic superior vertebral notch approach 


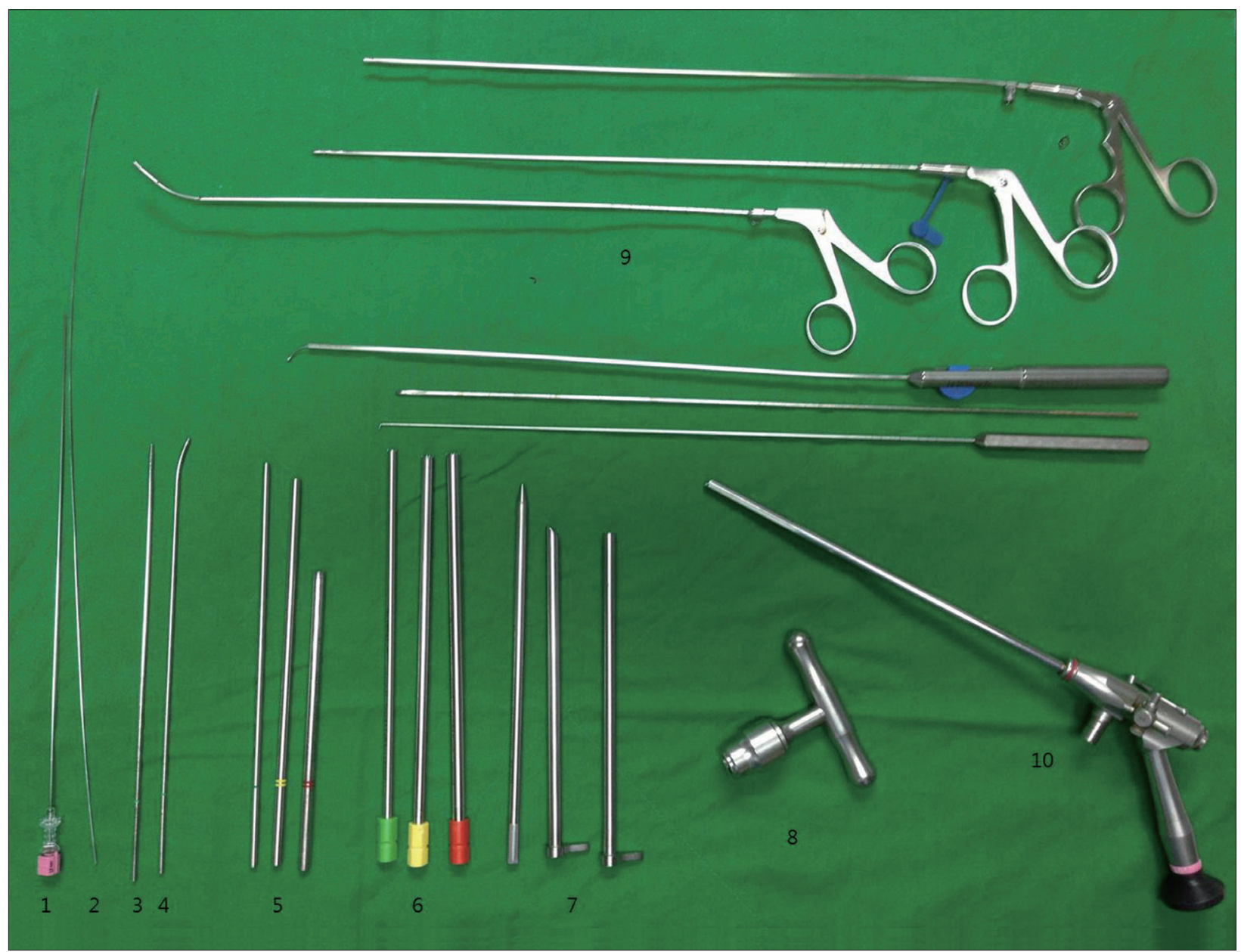

Fig. 3. Endoscopic instrument system $\left(\right.$ THESSYS $^{\circledR}$ ) for FSVNA 18-gauge needle (1), guide wire (2), straight guide rod (3), curved guide rod (4), guide tubes of increasing diameter (5), three reamers from $5.5 \mathrm{~mm}$ to $8.5 \mathrm{~mm}(6)$, working cannula (7), handle grip for the reamers (8), various grasping forceps (9), endoscope (10).
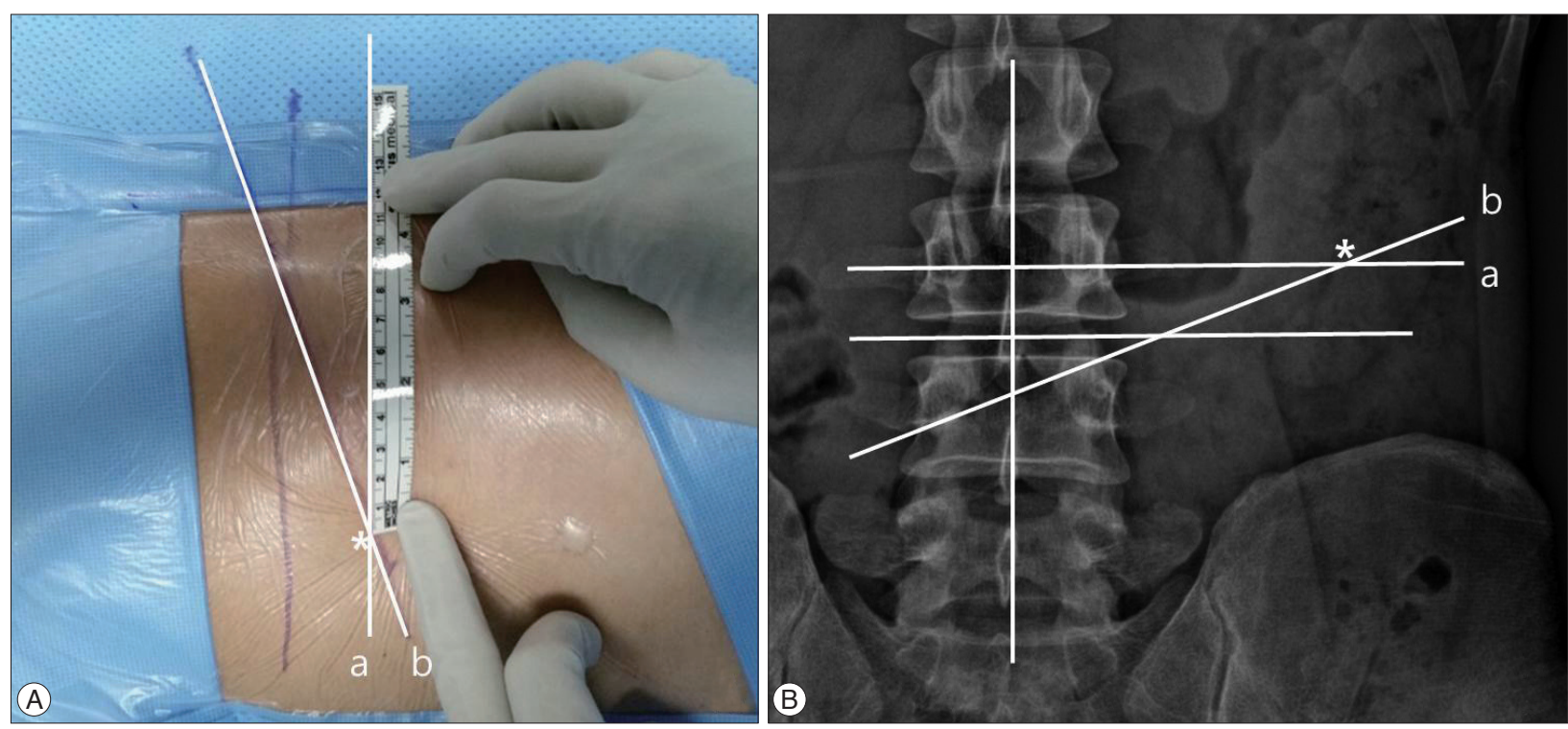

Fig. 4. Determination of skin entry point (A). Skin marking of entry point (B). Radiologic illustration of skin entry point in lumbar X-ray anteroposterior view. The point of intersection between the marked horizontal line (a) and the oblique directional line (b) gives the point of insertion of the needle. Asterisk : entry point. 
anatomy. A greater distance from the midline is preferable, if the patient is obese and/or has a very narrow foramen with facet arthrosis. The oblique caudal directional line is drawn from the superior margin of the ipsilateral pedicle to the inferior margin of contralateral pedicle in the X-ray orthogonal anteroposterior view. The approach angle in the $\mathrm{X}$-ray anteroposterior view should be readjusted by target area. A more caudal angle in inferior migrated cases and a less caudal angle in superior migrated cases are needed.

Needle insertion to target and dilation of soft tissue in approach pathway

The skin at the insertion site was infiltrated with approximately $5 \mathrm{~mL}$ Xylocaine ${ }^{\circledR}$ with adrenaline after discography by injecting $2 \mathrm{~mL}$ to $3 \mathrm{~mL}$ of a mixture of radio opaque dye, indigo carmine, and normal saline. An 18-gauge needle was advanced to the target, the superior vertebral notch of the lower vertebra, from the skin entry point. In this way, the needle often first meets the facet joint. The ideal point of entry for it is just slightly cranial to the facet joint (Fig. 5A, B). The 18-gauge needle was then further advanced through the foramen to the target superior vertebral notch and slid to the facet joint cautiously (Fig. 5C, D). Sometimes, the needle can go further into the epidural space between vertebral body and dural sac, passing over the medial pedicular line. Then, a guide wire was advanced through the 18-gauge needle, and the needle was removed (Fig. 5E, F). Next, a stab incision was made, approximately $5 \mathrm{~mm}$ long, in the region of the guide wire. First, the thinnest guide rod was advanced as far as the facet joint along the guide wire. Subsequently, three further guide tubes of increasing diameter were advanced over the cannulated guide rod, to widen the soft-tissue channel. The first two guide tubes were then removed. Through the last remaining guide tube, the facet joint was infiltrated with approximately 10 $\mathrm{mL}$ Xylocaine ${ }^{\mathbb{B}}$ with adrenaline by using a long, thin spinal needle.

\section{Guide rod and tube insertion and sequential reaming}

The guide rod was then advanced along the guide wire in a medial direction toward the herniated disk by careful hammer blows. Ideally, the tip of the guide rod should be advanced to the posterior vertebral body line under lateral image intensification, to the middle of the vertebral canal under anteroposterior imaging (Fig. 6A, B). In most cases, guide rod is docked firmly in the ideal position between the lower vertebral body and superior articular process (SAP) (Tip of the guide rod contacts the dorsal surface of lower vertebral body at the mid portion of the vertebral body. Dorsal surface of distal guide rod shaft contacts the ventral surface of SAP around foramen). In the case of severe facet hypertrophy, it is not easy to place the tip of the guide rod to ideal point. Instead of a straight guide rod, the use of a curved guide rod is recommended in those cases (Fig. 6C). A 3 -mm guide tube was advanced over the guide rod. The first reamer was inserted into the epidural space in the direction of
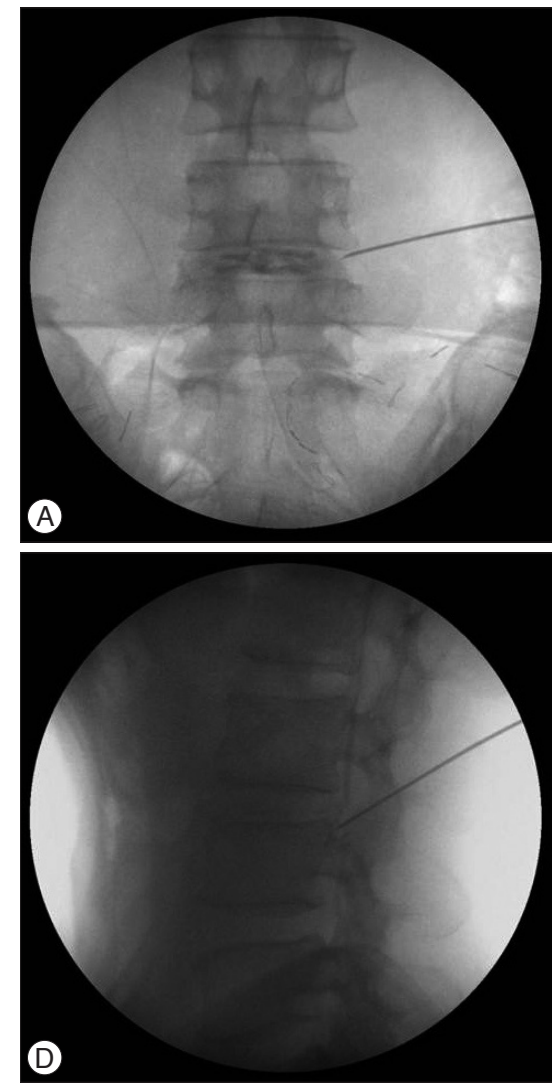

Fig. 5. A-F : Needle insertion to target.
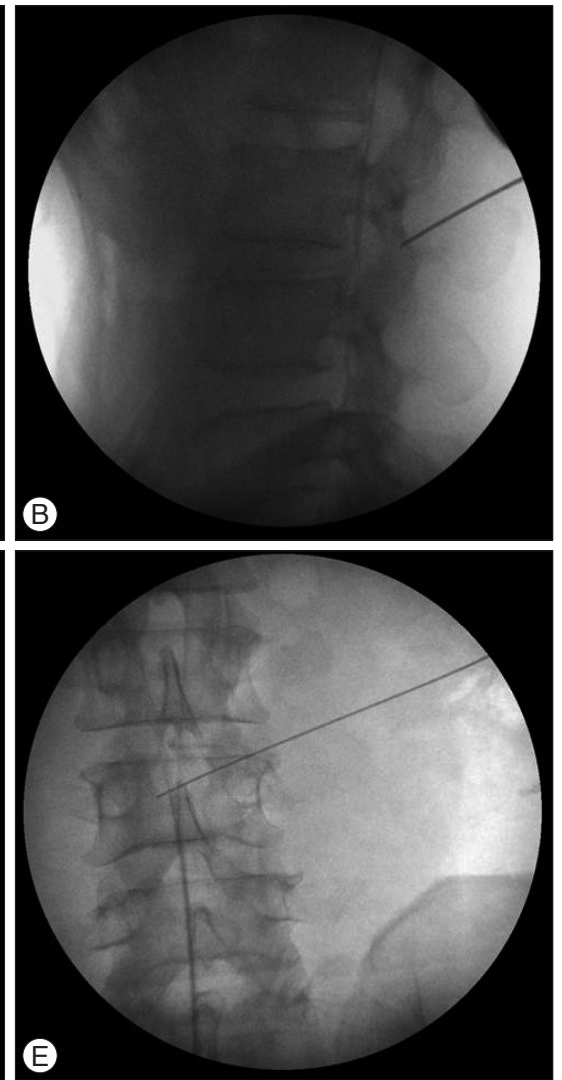
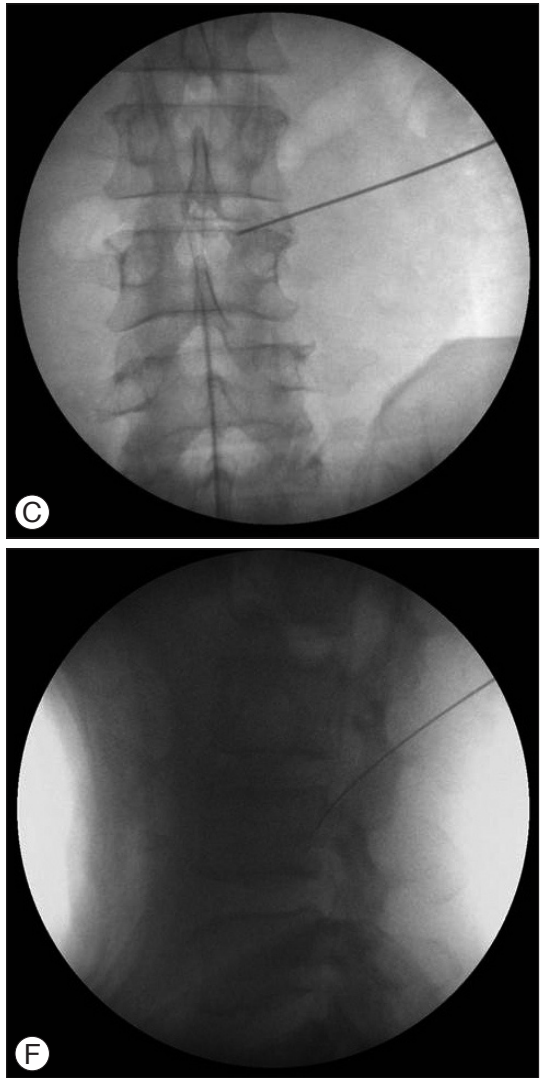
the disk herniation. Part of the facet joint was removed with the reamer and the neural foramen was widened. The reaming procedure is controlled radiologically in two planes. The reamers should not be advanced beyond the medial interpediculate line. A 4-mm guide tube is passed over the rod and then reaming with the next diameter reamer can be performed. This process is repeated until the foramen has been enlarged with a $7.5-\mathrm{mm}$ diameter reamer (Fig. 7A).

\section{Insertion of working cannula}

After removal of the last reamer used, the working cannula is advanced over the remaining guide rod and guide tube to the herniated disk. Then, the guide rod and guide tube are removed. The precise position of the working cannula is checked in two planes by imaging (Fig. 7B, C). The endoscope is introduced through the working cannula; the surroundings of the foramen are inspected. The remnant osseous fragments and thickened ligamentous material were removed using endoscopic forceps and Elman coagulator until the epidural space and dura were visualized. Generally, the herniated disk is easily recognized. Part of the compressed nerve can occasionally be seen medially (Fig. 8). Under endoscopic guidance, the discectomy is started. The rest of the procedure of removing disc material is not different from the conventional technique.

\section{RESULTS}

\section{Patient demographics}

In total, 589 patients underwent PELD with foraminoplasty with the superior vertebral notch approach from August 2012 to April 2014. Ultimately, 64 patients who meet the inclusion

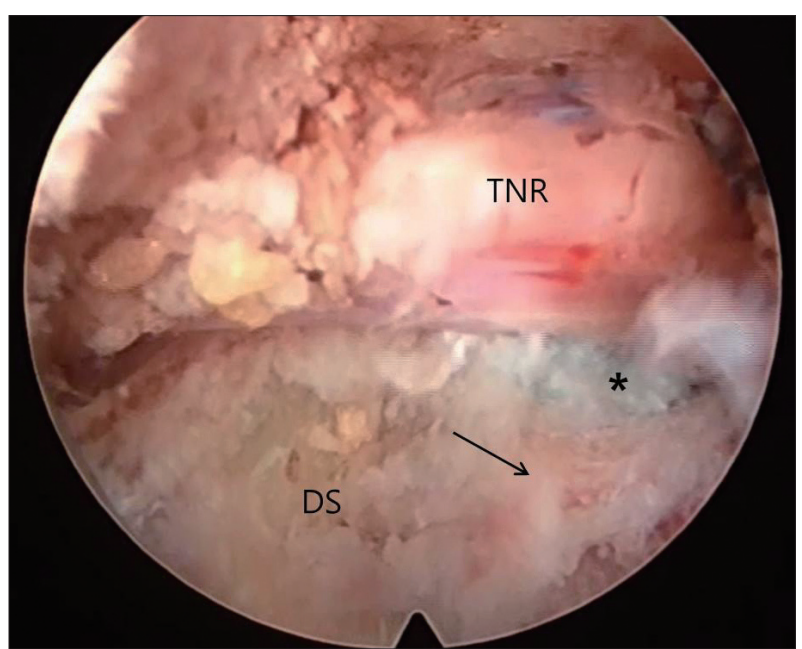

Fig. 8. Initial endoscopic view around the foramen after foraminoplasty with reamer. TNR : traversing nerve root, DS : disc space, Arrow : upper margin of lower vertebra, Asterisk : tail of ruptured disc.

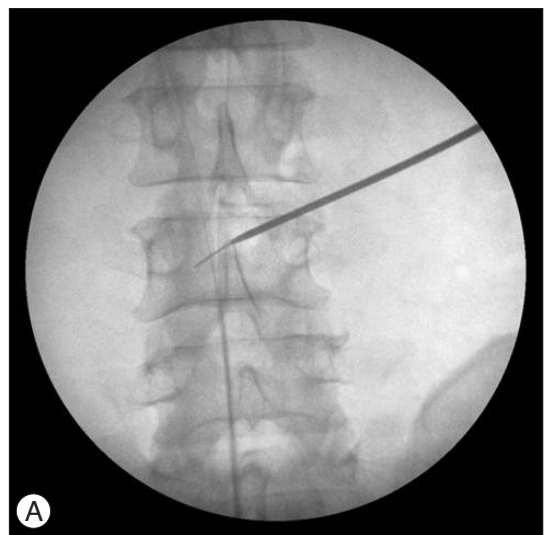

Fig. 6. A-C : Guide rod insertion.

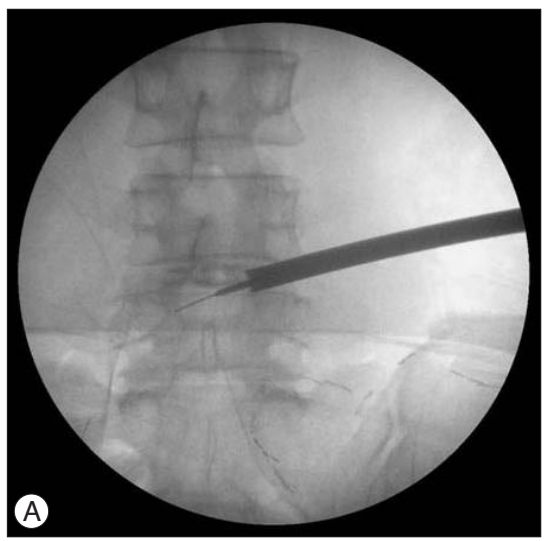

Fig. 7. A-C : Guide tube insertion and sequential reaming.
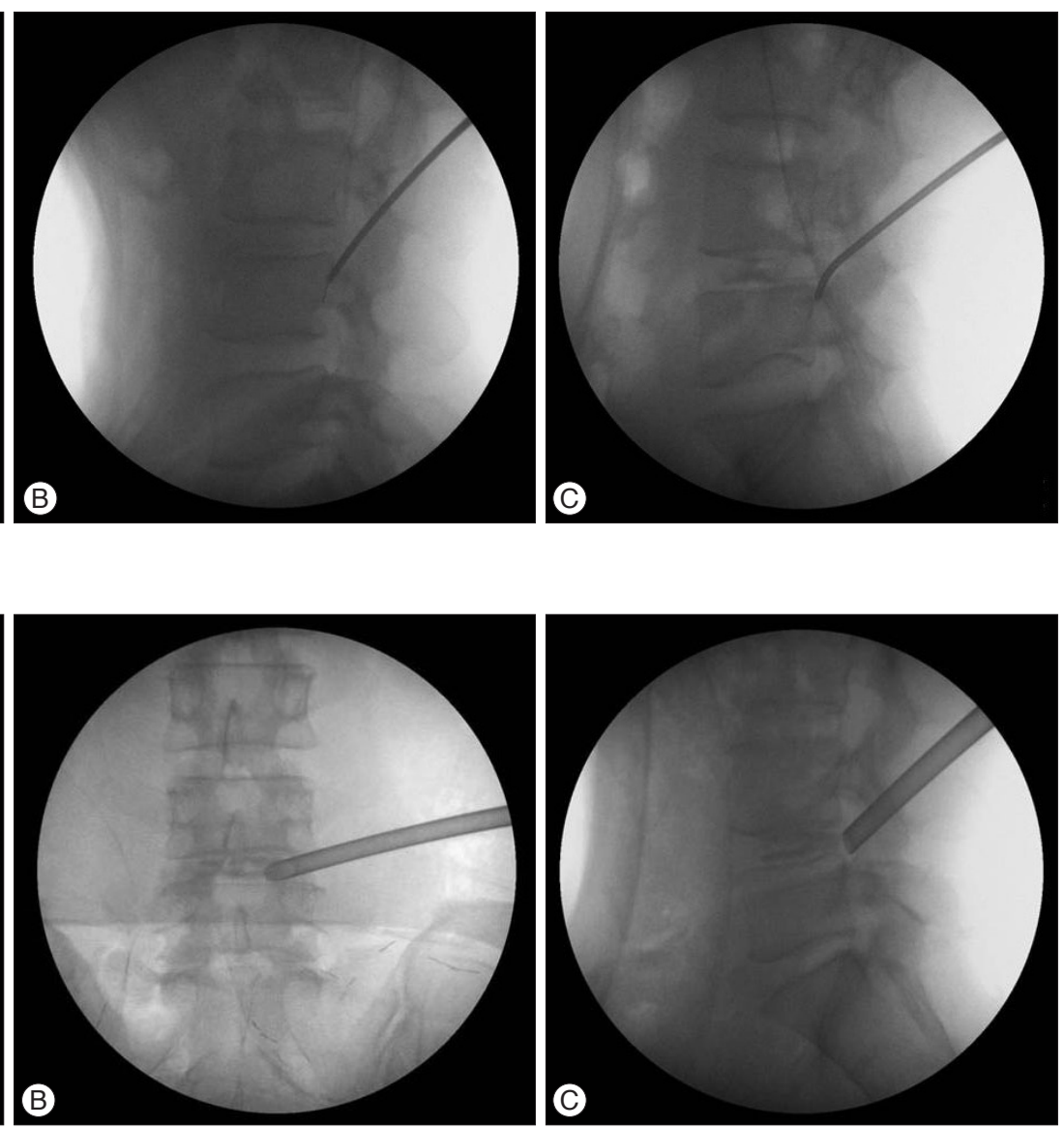

C 
criteria were included in this study [mean age : 52.73 (22-69), M/F : 55/32, L2-3/3-4/4-5/L5-S1 : 6/8/42/8, mean follow-up period : $12.2 \pm 4.2$ months]. Patients were preoperatively diagnosed with high grade migrated disc [superior $(n=18) /$ inferior $(n=28)]$, disc protrusion combined with moderate to severe foraminal stenosis $(\mathrm{n}=10)$, and high canal compromised disc $(n=8)$ (Table 1).

\section{Clinical and surgical outcomes}

The mean preoperative VAS score for leg pain was 8.24 (SD, 1.25). This score changed to 3.16, and, finally, 1.93 (SD, 1.78) at 6 weeks after surgery and at the last follow-up, respectively $(p<0.001)$ (Fig. 9A). The mean preoperative VAS score for back pain was 5.35 (SD, 2.22). This score improved to 3.05, and finally, 2.05 (SD, 1.57) at 6 weeks and the last follow-up, respectively $(p<0.001)$ (Fig. 9B). The mean preoperative ODI was $67.8 \%$ (SD, $15.4 \%)$. The mean postoperative ODI was $30.6 \%$, and finally,
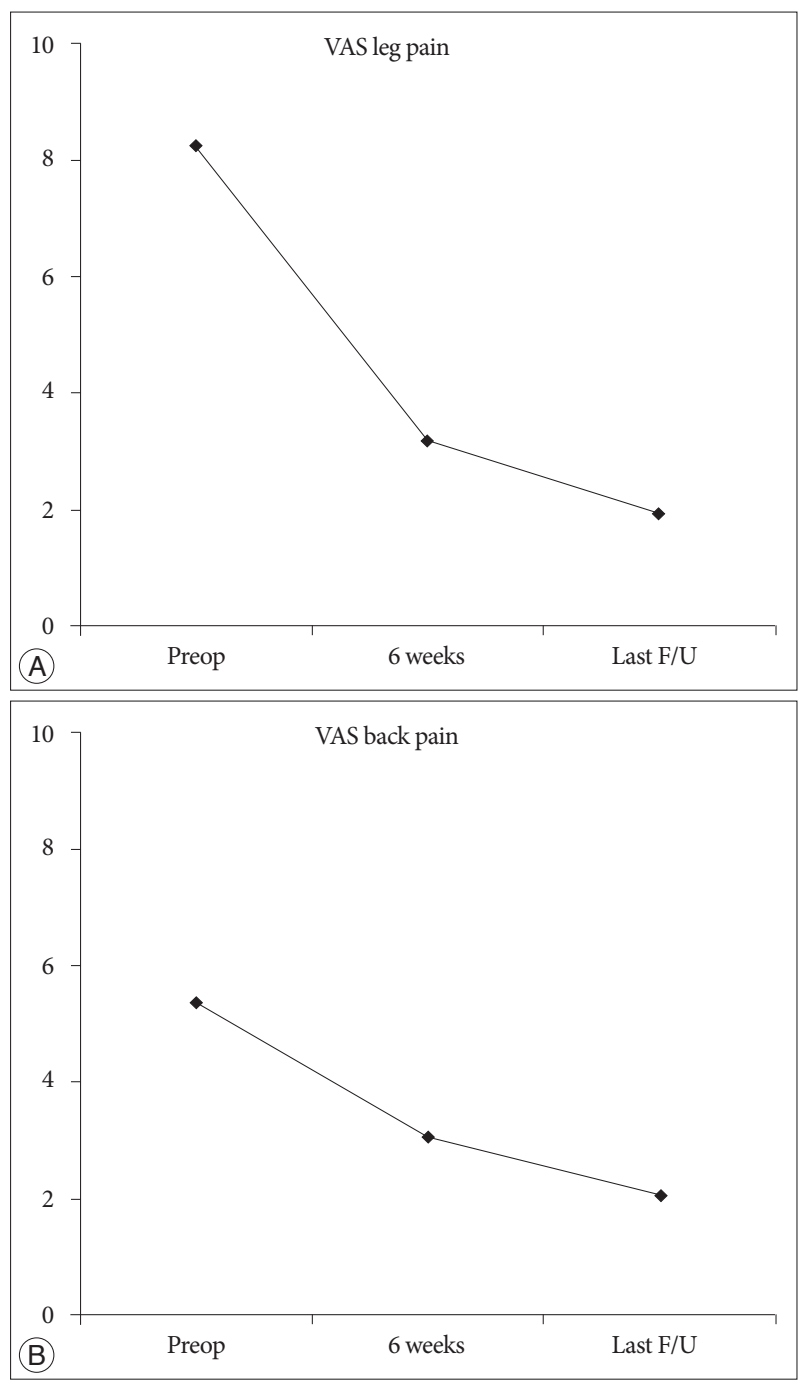

Fig. 9. A : Visual analog pain score (VAS) for radicular pain preoperatively and at 6 weeks, and at the final review post-surgery. B : VAS for back pain preoperatively, at 6 weeks, and at the final review post-surgery.
$17.14 \%$ (SD, 15.7\%) at 6 weeks and the last follow-up, respectively $(p<0.001)$ (Fig. 10). At the final follow-up review, the modified $\mathrm{MacNab}$ criteria were rated as follows : excellent in 45 patients (70.3\%), good in 16 patients (25\%), fair in 2 patients (3.1\%), and poor in 1 patient $(1.5 \%)$. Therefore, excellent or good results were obtained in $95.3 \%$ of the patients (Fig. 11). The mean operative time was 45.6 minutes per level (SD, 20.1 minutes; range, 35-98 minutes). The mean hospital stay after the procedure was 1.54 days (SD, 0.65 days; range, $1-4$ days). One patient required a subsequent endoscopic reoperation because of a disc protrusion that recurred three months postoperatively from the initial surgery. Two patients suffered from postoperative transient dysthesia in the same preoperative dermatomal distribution. Selective nerve block and oral gabapentin medication was given to both patients. Their symptoms improved over a 3-month period. There were no serious neurological deficits, dura tears, infections or cauda equina syndrome in the present study series.

\section{DISCUSSION}

PELD is the centerpiece of the minimally invasive surgery techniques. Compared to traditional open microdiscectomy, PELD has many merits like fewer complications and morbidities in the elderly, shorter hospital stays, earlier return to normal activity and thus, higher patient satisfaction ${ }^{3,6,9,25)}$. Many reports also showed that endoscopic disc surgery by experienced surgeons can achieve favorable clinical results equivalent to the

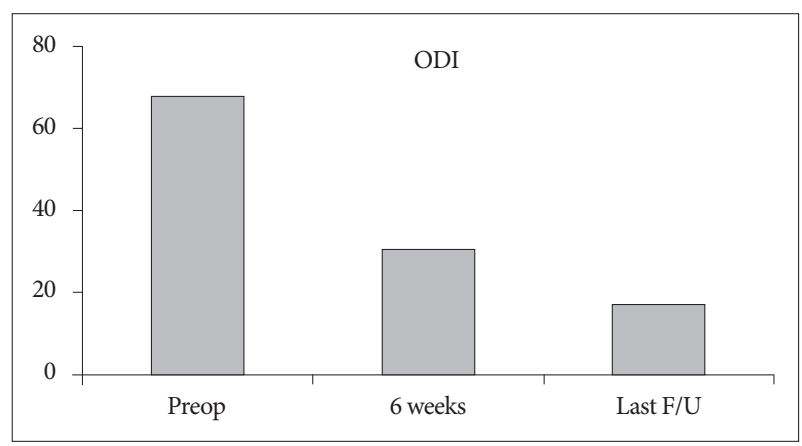

Fig. 10. Oswestry disability index (ODI) scores preoperatively, at 6 weeks, and at the final review post-surgery.

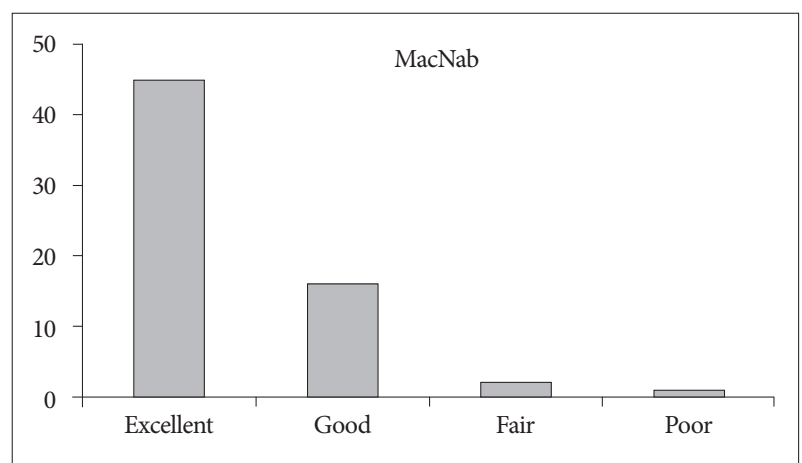

Fig. 11. The global outcome according to the modified MacNab criteria. Sixty-one of the 64 patients (95.3\%) experienced excellent or good results. 
standard microsurgical technique $\mathrm{e}^{3,14,17,20,21)}$. Despite such numerous advantages and inspiring clinical results, endoscopic discectomy has not been universally adopted. There are several reasons for this, including the steep learning curve, anatomical limitations during endoscopic approach, and intraoperative complications. Some cases such as highly migrated, compromised high canal, combined with foraminal stenosis have been considered as relative contraindications in performing PELD, especially to those just beginning career in endoscopic spine surgery ${ }^{16,18)}$. The incidence of failure was significantly higher in those cases due to problems like inadequate exposure, poor visualization, and an inability to reach and grasp herniated fragments. Several approaches and techniques were developed to overcome such limitations and prevent complications. Some surgeons reported other methods, such as the extreme lateral approach, epiduroscopic approach, and suprapedicular approach solve difficult epidural pathology ${ }^{4,8,16,22)}$.

Percutaneous endoscopic foraminoplasty techniques have also been performed by many authors as a useful surgical strategy in such limited indications of PELD, and they have reported successful clinical outcomes of PELD combined with foraminoplasty $^{2,5,7,11,12,19,24,29)}$.
Our results also showed that the foraminoplasty technique is helpful to achieve favorable clinical outcomes of relatively contraindicated case for conducting PELD, such as in highly migrated cases, compromised high canal cases, and cases accompanied by foraminal stenosis. The global success rate in our series was 95.3\%. Our surgical data demonstrated a favorable clinical outcome with a relatively low complication rate. It is inspiring that we acquired these results although we didn't include the result of rest of 535 patients who were followed-up but not included in this study because they were thought to be traditionally usual cases in PELD and expected to show better clinical results. These outcomes are comparable to those of other endoscopic techniques (Table 3). The overall success rates of the case series ranged from $88 \%$ to $95 \%$. We think that a direct comparison among those studies is difficult because the type of pathologies and operative technique might be somewhat different. However, it would be helpful to estimate the efficacy of FSVNA compared to other various PELD techniques.

Above all things, the greatest advantage of the foraminoplasty technique is that it allows the surgeon to see enough spinal canal so the pathologic lesion in the epidural space can be easily managed, as compared to the previous conventional endoscopic ap-

Table 3. Comparison of clinical and surgical results with other percutaneous endoscopic lumbar discectomy for lumbar disc herniation

\begin{tabular}{|c|c|c|c|c|c|c|c|c|c|}
\hline Author & $\begin{array}{c}\text { Year of } \\
\text { publication }\end{array}$ & $\begin{array}{l}\text { No. of } \\
\text { patients }\end{array}$ & $\begin{array}{l}\text { Follow-up } \\
\text { period }\end{array}$ & Pathology & $\begin{array}{l}\text { Operation } \\
\text { time (min) }\end{array}$ & $\begin{array}{l}\text { Hosiptal } \\
\text { stay (d) }\end{array}$ & $\begin{array}{l}\text { Technique } \\
\text { (anesthesia) }\end{array}$ & $\begin{array}{l}\text { Success } \\
\text { rate }(\%)\end{array}$ & $\begin{array}{l}\text { Complication and } \\
\text { revision surgery }\end{array}$ \\
\hline $\begin{array}{l}\text { Yeong and } \\
\text { Tsou }\end{array}$ & 2002 & 307 & $23 \mathrm{mo}$ & $\begin{array}{l}\text { Intracanal } \\
\text { noncontained }\end{array}$ & & & $(\mathrm{L})$ & 89.3 & $\begin{array}{l}6 \text { dysthesia } \\
2 \text { thrombophlebitis } \\
2 \text { deep infection } \\
1 \text { dura tear } \\
13 \text { reoperation }\end{array}$ \\
\hline $\begin{array}{l}\text { Schubert } \\
\text { and } \\
\text { Hoogland }^{24)}\end{array}$ & 2005 & 611 & $2 y$ & $\begin{array}{l}\text { Every form of } \\
\text { herniated } \\
\text { intervertebral } \\
\text { disc }\end{array}$ & 50 & & $\begin{array}{l}\text { PELD with } \\
\text { foramionoplasty } \\
\text { (L) }\end{array}$ & 95.3 & $\begin{array}{l}3 \text { dysthesia } \\
1 \text { motor weakness } \\
15 \text { reoperation } \\
\text { (endoscopic) } \\
7 \text { conventional } \\
\text { open discectomy } \\
1 \text { total disc } \\
\text { replacement }\end{array}$ \\
\hline $\begin{array}{l}\text { Reutten } \\
\text { et al. }{ }^{22)}\end{array}$ & 2007 & 232 & $2 y$ & $\begin{array}{l}\text { Extra-, } \\
\text { intraforaminal } \\
\text { and } \\
\text { intracanalicular }\end{array}$ & $23(13-46)$ & $22(5-41)$ & $\begin{array}{l}\text { PELD with } \\
\text { endoscopic } \\
\text { laminotomy } \\
\text { foraminoplasty } \\
\text { (G) }\end{array}$ & 92 & $\begin{array}{l}9 \text { dysthesia } \\
14 \text { reoperation } \\
\text { (endoscopic) } \\
10 \text { conventional } \\
\text { revision surgery }\end{array}$ \\
\hline Choi et al. ${ }^{5)}$ & 2008 & 59 & $25.4 \mathrm{mo}$ & Highly migrated & & 1.4 & $\begin{array}{l}\text { PELD with } \\
\text { foraminoplasty } \\
\text { (L) }\end{array}$ & 91.4 & $\begin{array}{l}2 \text { reoperation } \\
\text { (endoscopic) } \\
2 \text { conventional } \\
\text { open discectomy }\end{array}$ \\
\hline Chae et al. ${ }^{4)}$ & 2009 & 53 & $9.84 \mathrm{mo}$ & $\begin{array}{l}\text { Highly inferior } \\
\text { migrated }\end{array}$ & $90(30-150)$ & 1.33 & $\begin{array}{l}\text { Suprapedicular } \\
\text { approach }(E)\end{array}$ & 88.8 & 7 dysthesia \\
\hline $\begin{array}{r}\text { Present } \\
\text { study }\end{array}$ & & 64 & $6-25 \mathrm{mo}$ & $\begin{array}{l}\text { Highy migrated, } \\
\text { High canal } \\
\text { compromised, } \\
\text { combined with } \\
\text { foraminal stenosis }\end{array}$ & $45.6(35-98)$ & $\begin{array}{c}1.54 \\
(\mathrm{SD}, 0.65)\end{array}$ & FSVNA (L) & 95.3 & $\begin{array}{l}2 \text { dysthesia } \\
1 \text { reoperation } \\
\text { (endoscopic) }\end{array}$ \\
\hline
\end{tabular}


proach, in which operative view was mostly confined to subligamentous annular level. Such merits enable surgeons not only to see enough epidural space but also to have the route to navigate, find the lesion and reach the relatively hidden zone far from disc space ${ }^{5,19)}$. The foraminoplasty technique is useful in highly migrated discs, especially in downward migrated discs. In most cases in which foraminoplasty is used, the decompression of the traversing nerve root in the epidural space could be confirmed at the end stage of procedure directly with endoscopic vision, not by the indirect pulsation of soft tissue like the posterior longitudinal ligament or remnant annulus (Fig. 8).

Central herniation with high-grade canal compromise showed the highest rate of operative failure, and the rate was significantly different between low- and high-grade canal compromised groups $^{18)}$. The current technique is basically an "outside-in" technique. In high canal compromised cases, current approach makes it possible to remove the hernia mass occupying the epidural space by just grasping the tip of the hernia mass in the endoscopic view at the subannular portion and pulling it toward the disc without removing nonpathological intradiscal nucleus tissue. Thus, it minimize the chance of neural and nonpathological disc nucleus injury which can occur during the "inside-out" technique to obtain a intradiscal working tunnel or a cavity ${ }^{15,27,28)}$.

FSVNA is different from previous foraminoplasty techniques in several aspects. Previous foraminoplasty techniques requiring a reamer, which was a floating technique in the foramen region, allowing the shifting of the guiding tube's position or allowing it to slide into the cranial area of the foramen during the reaming procedure. This could lead to ineffective reaming and injury to the upper root. But in the current technique, the guide rod and tube are docked between the SAP and lower vertebral vertebral body. This allows for stable reaming without slipping and shifting of the reaming axis. Stable foraminoplasty, not shifted ventrally or cranially, allows the endoscope to be placed more dorsally close to the epidural space and more caudally far from the upper root, leading to a lower risk of interrupting the disc structure and upper exiting root.

In FSVNA, docking by guide rod is accomplished between dorsal surface of lower vertebral body and ventral surface of superior articular process, not merely at the outskirt of the foramen. Approach angle in axial plane is more crucial than the size of the foramen during docking step of guide rod. Real surgical corridor between lower vertebral body and SAP for initial docking is very narrow. Inclined angle of guide rod axis in axial plane enables this docking maneuver. Precise and meticulous initial needling before the placement of guide wire is tremendously important for the success of docking procedure. It is more easy to get this approach angle in the case which have large foramen. But, sometimes, in the case with stenotic foramen by hypertrophied facet which has very narrow space between lower vertebral body and SAP, it is more difficult. Curved guide rod is needed because such a case doesn't provide enough axial inclination angle anatomically for initial guide rod docking by a straight guide rod.

The previous foraminoplasty technique is considered to be challenging; it has steep learning curve and needs a relatively long operation time and expensive endoscopic instruments, like lasers and endoscopic drills, are required. But, the FSVNA procedure itself is simple and takes a very small amount of time (5-10 minutes). It is performed by reamers under $\mathrm{C}$-arm guidance. The endoscopic drill was selectively used in the case of widening the foramen and when decompression of the upper root was needed. But, in most cases it was not necessary.

Neural injury is a point of concern because the current procedure is a blind technique. But, the first structure we encounter in the endoscopic view at the initial stage of the endoscopic surgery after reaming is mostly ligament flavum beyond the sculpted superior articular facet. Ligament flavum and facet capsule function as an anatomical barrier to prevent neural injury from the reamer in foraminoplasty. It is important to not advance the reamer over the medial pedicular line. There were no cases of nerve root injury or dural tear during approach in this clinical series.

Another concern in foraminoplasty is bleeding from an injury to the venous sinus. The endoscopic reamer pushed the resected bone fragment into the location of the venous sinus channel, the sinus was naturally blocked, inducing natural hemostasis. Most of intraoperative bleeding was minimal and spontaneously controlled by compression with the working cannula, as other authors reported ${ }^{12,19,24)}$.

An advantage of FSVNA is also that it minimizes approachrelated complications. Motor weakness and temporary dysthesia have been reported previously as most common complications in PELD. These complications showed an incidence of $2-6.53 \%$ according to the authors ${ }^{1,10,13,21,23)}$. The symptoms are
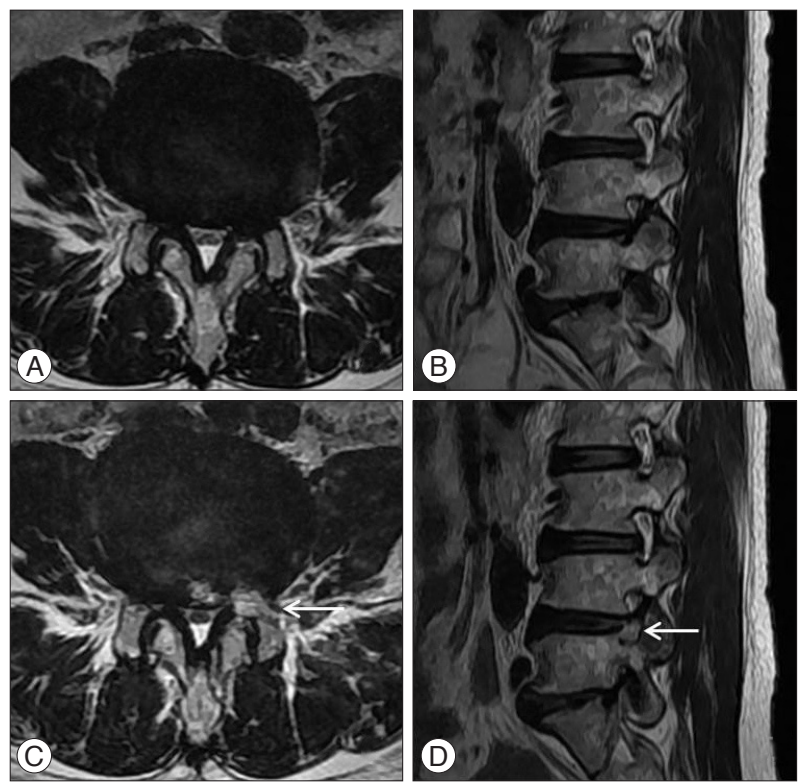

Fig. 12. Illustrated case of a 68-year-old female patient. A and B : Preoperative MR images showing severe foraminal stenosis at the Lt. L4-5 level. C and D : Postoperative MR images showing resected area (arrow) by reamer to provide safe approach route. 
postulated to come from an irritation of the exiting root or traversing root during the operation. From the results of our current study, the incidence of postoperative dysthesia or motor weakness due to upper root injury was relatively low compared to the incidences reported by other studies. Confirmation of the safe triangle is important preventing this problem. In FSVNA, the space between SAP and lower vertebral body for initial docking by first guide rod is very narrow as mentioned above. But serial guide rod dilation and reaming make more space gradually for next size guide rod docking. Resection area by sequential reaming is ventral portion of SAP. These resected area is most safe anatomical point around Kambin's triangle and most far from the upper root. FSVNA is performed securely through this newly created surgical space (Fig. 12). It is advantageous when the surgeon approaches and manipulates the working cannula in the safe zone around the foraminal area. We assume that is why the incidence of upper root injury is remarkably low during the approach and entire procedure in FSVNA.

There were the cases which had already enough large foramen preoperatively. In some cases, no contact of bony structure around foramen was recognized during the first reaming. But, even in the case of large foramen, foraminoplasty was useful to trim the structures around the foramen, like the foraminal ligament and facet capsule, and allows the surgeon to acquire a better endoscopic operative view during the initial stage of the endoscopic procedure. Considering that the time consumed during foraminoplasty was, at most, about 10 minutes, foraminoplasty with reamers is worthwhile as a preparative procedure in selective cases of PELD.

But, regarding the limitations of this technique, in highly superior migrated cases, we experienced some difficulty manipulating the working channel cranially after approach, especially in obese and muscular patients because the initial angle of the working channel was slightly caudal in the coronal plane. But this limitation was overcome by readjusting the guide tube angle more cranially when reaming after placement of the guide rod. A more caudal approach at the upper level from the index level was also another good option to resolve the highly superior migrated cases. Because, as mentioned before, FSVNA is very useful in exploring the pathology which is located caudally.

We evaluated the feasibility of FSVNA in PELD in 64 cases. However, the absolute number of cases and follow-up period are not enough to compare the clinical outcome and the incidence of complications with previous reports. Further longterm study is required to prove the procedure's clinical efficacy and benefit in preventing real incidences of complications. In spite of these limitations, our results show that FSVNA is a safe and reliable method to acquire a favorable clinical outcome in limited indications for PELD.

\section{CONCLUSION}

FSVNA with foraminoplasty with reamers is an effective and affordable minimally invasive procedure for patients in relatively limited indications for PELD, showing both a high success rate in terms of clinical outcomes and a low complication rate due to its safe approach.

\section{References}

1. Ahn Y, Lee SH, Lee JH, Kim JU, Liu WC: Transforaminal percutaneous endoscopic lumbar discectomy for upper lumbar disc herniation : clinical outcome, prognostic factors, and technical consideration. Acta Neurochir (Wien) $151:$ 199-206, 2009

2. Ahn Y, Oh HK, Kim H, Lee SH, Lee HN : Percutaneous endoscopic lumbar foraminotomy : an advanced surgical technique and clinical outcomes. Neurosurgery 75 : 124-133; discussion 132-133, 2014

3. Birkenmaier C, Komp M, Leu HF, Wegener B, Ruetten S: The current state of endoscopic disc surgery : review of controlled studies comparing full-endoscopic procedures for disc herniations to standard procedures. Pain Physician 16 : 335-344, 2013

4. Chae KH, Ju CI, Lee SM, Kim BW, Kim SY, Kim HS : Strategies for noncontained lumbar disc herniation by an endoscopic approach : transforaminal suprapedicular approach, semi-rigid flexible curved probe, and 3-dimensional reconstruction CT with discogram. J Korean Neurosurg Soc 46 : 312-316, 2009

5. Choi G, Lee SH, Lokhande P, Kong BJ, Shim CS, Jung B, et al. : Percutaneous endoscopic approach for highly migrated intracanal disc herniations by foraminoplastic technique using rigid working channel endoscope. Spine (Phila Pa 1976) 33 : E508-E515, 2008

6. Donceel P, Du Bois M : Fitness for work after surgery for lumbar disc herniation : a retrospective study. Eur Spine J 7 : 29-35, 1998

7. Endoscopic laser foraminoplasty. Clin Privil White Pap (60) : 1-13, 2012

8. Han IH, Choi BK, Cho WH, Nam KH : The obturator guiding technique in percutaneous endoscopic lumbar discectomy. J Korean Neurosurg Soc 51 : 182-186, 2012

9. Hermantin FU, Peters T, Quartararo L, Kambin P : A prospective, randomized study comparing the results of open discectomy with those of video-assisted arthroscopic microdiscectomy. J Bone Joint Surg Am 81 : 958-965, 1999

10. Kambin P, Zhou L : Arthroscopic discectomy of the lumbar spine. Clin Orthop Relat Res (337) : 49-57, 1997

11. Knight MT, Ellison DR, Goswami A, Hillier VF : Review of safety in endoscopic laser foraminoplasty for the management of back pain. J Clin Laser Med Surg 19: 147-157, 2001

12. Knight MT, Goswami A, Patko JT, Buxton N : Endoscopic foraminoplasty : a prospective study on 250 consecutive patients with independent evaluation. J Clin Laser Med Surg 19: 73-81, 2001

13. Lee DY, Lee SH : Learning curve for percutaneous endoscopic lumbar discectomy. Neurol Med Chir (Tokyo) 48 : 383-388; discussion 388-389, 2008

14. Lee DY, Shim CS, Ahn Y, Choi YG, Kim HJ, Lee SH : Comparison of percutaneous endoscopic lumbar discectomy and open lumbar microdiscectomy for recurrent disc herniation. J Korean Neurosurg Soc 46 : 515-521, 2009

15. Lee SH, Choi KC, Baek OK, Kim HJ, Yoo SH : Percutaneous endoscopic intra-annular subligamentous herniotomy for large central disc herniation : a technical case report. Spine (Phila Pa 1976) 39: E473-E479. 2014

16. Lee S, Kim SK, Lee SH, Kim WJ, Choi WC, Choi G, et al. : Percutaneous endoscopic lumbar discectomy for migrated disc herniation : classification of disc migration and surgical approaches. Eur Spine J 16 : 431-437, 2007

17. Lee SH, Chung SE, Ahn Y, Kim TH, Park JY, Shin SW : Comparative radiologic evaluation of percutaneous endoscopic lumbar discectomy and open microdiscectomy : a matched cohort analysis. Mt Sinai J Med 73 : 
795-801, 2006

18. Lee SH, Kang BU, Ahn Y, Choi G, Choi YG, Ahn KU, et al. : Operative failure of percutaneous endoscopic lumbar discectomy : a radiologic analysis of 55 cases. Spine (Phila Pa 1976) 31 : E285-E290, 2006

19. Lee SH, Kang HS, Choi G, Kong BJ, Ahn Y, Kim JS, et al. : Foraminoplastic ventral epidural approach for removal of extruded herniated fragment at the L5-S1 level. Neurol Med Chir (Tokyo) 50 : 1074-1078, 2010

20. Ruetten S, Komp M, Merk H, Godolias G : Full-endoscopic anterior decompression versus conventional anterior decompression and fusion in cervical disc herniations. Int Orthop 33 : 1677-1682, 2009

21. Ruetten S, Komp M, Merk H, Godolias G : Surgical treatment for lumbar lateral recess stenosis with the full-endoscopic interlaminar approach versus conventional microsurgical technique : a prospective, randomized, controlled study. J Neurosurg Spine 10 : 476-485, 2009

22. Ruetten S, Komp M, Merk H, Godolias G : Use of newly developed instruments and endoscopes : full-endoscopic resection of lumbar disc herniations via the interlaminar and lateral transforaminal approach. J Neurosurg Spine 6 : 521-530, 2007

23. Savitz MH, Doughty H, Burns P : Percutaneous lumbar discectomy with a working endoscope and laser assistance. Neurosurg Focus 4 : e9,
1998

24. Schubert M, Hoogland T : Endoscopic transforaminal nucleotomy with foraminoplasty for lumbar disk herniation. Oper Orthop Traumatol 17 : 641-661, 2005

25. Segnarbieux F, Van de Kelft E, Candon E, Bitoun J, Frèrebeau P : Discocomputed tomography in extraforaminal and foraminal lumbar disc herniation : influence on surgical approaches. Neurosurgery 34 : 643 647; discussion 648, 1994

26. Wildermuth S, Zanetti M, Duewell S, Schmid MR, Romanowski B, Benini A, et al. : Lumbar spine : quantitative and qualitative assessment of positional (upright flexion and extension) MR imaging and myelography. Radiology 207 : 391-398, 1998

27. Yeung AT : The evolution of percutaneous spinal endoscopy and discectomy : state of the art. Mt Sinai J Med 67 : 327-332, 2000

28. Yeung AT, Tsou PM : Posterolateral endoscopic excision for lumbar disc herniation : surgical technique, outcome, and complications in 307 consecutive cases. Spine (Phila Pa 1976) 27 : 722-731, 2002

29. Yeung AT, Yeung CA : Advances in endoscopic disc and spine surgery : foraminal approach. Surg Technol Int $11: 255-263,2003$ 